\title{
Risk Management in Obstetric Care for Family Physicians: Results of a 10-Year Project
}

\author{
Thomas S. Nesbitt, MD, MPH, Allen Hixon, MD, Jeffrey L. Tanji, MD, \\ Joseph E. Scherger, MD, MPH, and Dana Abbott
}

Background: Malpractice issues within the United States remain a critical factor for family physicians providing obstetric care. Although tort reform is being widely discussed, little has been written regarding the malpractice crisis from a risk management perspective.

Methods: Between 1989 and 1998, a 10-year risk management study at the UC Davis Health System provided a unique collaboration between researchers, a mutual insurance carrier and family physicians practicing obstetrics. Physicians were asked to comply with standardized clinical guidelines, attend continuing medical education (CME) seminars, and submit obstetric medical records for review. Feedback analysis was provided to each physician on their records, and the insurance carrier tracked interim malpractice claims.

Results: One hundred and ninety-four physicians participated, attending to 32,831 births. Compliance with project guidelines was $\mathbf{9 1 \%}$. Five closed obstetric cases were reported with only one settlement reported to the National Provider Data Bank. Physicians believed the project was beneficial to their practices.

Conclusions: Family physicians practicing obstetrics are willing to participate in a collaborative risk management program and are compliant with standardized clinical guidelines. The monetary award for successful malpractice claims was relatively low. This collaborative risk management model may offer a potential solution to the current malpractice crisis. (J Am Board Fam Pract 2003;16:471-7.)

Malpractice issues have been a major barrier to the provision of maternity care for the past several decades. Recent reports suggest that malpractice awards are increasing and the majority of carriers raised rates in 2001. ${ }^{1}$ The problem has reached such crisis proportion nationally that physicians are dropping obstetrics from their practices and hospitals are closing obstetric units, exacerbating the access problems for pregnant women. Although the United States Congress and many state legislatures are currently wrestling with tort reform, little has been written addressing this crisis from a risk management perspective.

Submitted, revised 18 September 2003.

From Outreach, TeleHealth and CME (TSN), University of California, Davis (JLT, DA), University of Connecticut (AH); School of Medicine, Florida State University (JES), and University of California, Davis. Address correspondence to Thomas S. Nesbitt, MD, MPH, Center for Health and Technology, UC Davis Health System, 2300 Stockton Blvd., Sacramento, CA 95817.

Grant funding for this project was provided by The California Academy of Family Physicians Foundation and by NORCAL Mutual Insurance Company.
Only a decade ago, a report by the Institute of Medicine noted that 9 national studies and 23 state studies cited liability concerns as a primary reason for the loss of obstetric providers. ${ }^{2}$ This report concluded that it was not clear whether the cost of liability premiums constituted a real economic burden to obstetric providers; however, costs were a greater burden for family physicians compared with obstetricians. $^{2}$

The decade of the 1980s was a period of dramatic decrease in the percentage of family physicians providing obstetric services. ${ }^{3}$ Between 1986 and 1992, the participation rate for family physicians practicing obstetrics decreased from $46 \%$ to $24.2 \% .^{4}$ Several states saw even more dramatic losses of family physicians from many areas, most of them rural, without adequate obstetric services. ${ }^{5}$ In Pennsylvania, where the crisis has become extreme over the past year, physicians are dropping obstetrics from their practices, forcing women to travel extensive miles for care. ${ }^{6}$

Research has demonstrated that poor local access to obstetric services in rural areas is associated 
with an increase in adverse birth outcomes. ${ }^{7,8} \mathrm{~A}$ study published in 1997 showed that poor local access to providers of obstetrics care was associated with a significantly greater risk of having a nonnormal neonate for both Medicaid and privately insured patients. In addition, for privately insured patients, poor local access to care was consistently associated with higher charges and increases hospital length of stay. ${ }^{8}$

Studies that focus specifically on family physicians have revealed that the cost of the premiums and the fear of potential lawsuits are the most commonly cited reasons for discontinuing obstetrics. $^{9-11}$ Although some studies have suggested other reasons, liability issues seem to play a major role in initiating a cascade of events that has resulted in less than one third of family physicians providing a service for which they have required training in residency programs. ${ }^{12,13}$

During the last malpractice crisis in California, approximately $50 \%$ of all family physicians who practiced obstetrics in the early 1980s had discontinued doing so by the end of the decade. ${ }^{3}$ In some areas of the state, there were even more significant declines in participation and maternity care by family physicians. One northern California study of 26 counties reported that 167 family physicians outside of academics were providing obstetric care in 1985; only 67 continued by $1990 .{ }^{14}$ This occurred during a time when malpractice insurance premiums approximately doubled relative to reimbursement. In 1992, the average difference in premium for a family physician in California who included obstetrics in the practice was approximately $\$ 13,000$, a $162 \%$ difference in premium compared with family physicians who did not provide this service to their patients. ${ }^{15}$

The specific goals of this collaborative study were to determine whether obstetrically active, board-certified family physicians would comply with a risk management program and to monitor the experience of successful malpractice suits over a 10 -year period for these physicians.

\section{Methods \\ Subjects}

Participants in this project were recruited through California malpractice insurance carriers, from the California Academy of Family Physicians memberships, the American Academy of Family Physicians memberships, and through continuing medical education (CME) events sponsored by these organizations.

Physicians who were interested in participation were included only if their claims history met certain criteria based on the number of years in practice and the number of claims during that period; however, no participant had more than 3 obstetric claims. (Only one applicant was not selected to participate because of an inordinately high number of previous claims.) New participants were allowed to join the project during the 10 -year study as long as they met established criteria. Physicians included in the analysis were those who met the initial criteria, submitted records for review for at least one of the required submission periods, and were insured by the carrier cosponsoring this program. Physicians who dropped out of the study were still included in the claims analysis if the event occurred during the 10-year period. All were board-certified in family practice and had active obstetric practices.

\section{Institutional Review Board}

The University of California, Office of Human Research Protection (OHRP) reviewed and approved this project before initiation of the study. The study methodology met the Federal Guidelines Exemption Category [45 CFR 46/101(b)]. All local and Federal Guidelines for the protection of human subjects were strictly followed throughout the study period. Moreover, all identifiers were removed from physician and patient records before review, and patient and physician confidentiality was maintained as outlined in the OHRP and Federal guidelines.

\section{Requirements}

Before study enrollment, physicians were required to fill out an initial application documenting demographic information, their education and training, board certification, number of deliveries, and their malpractice claims history. They were also required to submit the prenatal care forms used in their practice for review and approval.

Participants agreed to practice by a set of obstetric guidelines for consultation and referral. Table 1 represents a list of guidelines. Every 4 months, project participants were required to submit a $\log$ of all births they attended. They were also required to submit every fourth record from women who experienced a normal vaginal obstetric 


\begin{tabular}{|c|c|c|c|}
\hline Category I & Category II & Category III & Category IV \\
\hline $\begin{array}{l}\text { For the following patient } \\
\text { problems, the family } \\
\text { physician must share } \\
\text { responsibility or refer to a } \\
\text { board-certified obstetrician- } \\
\text { gynecologist (OB/GYN) or } \\
\text { perinatal specialist. The } \\
\text { family physician may } \\
\text { participate in patient care } \\
\text { under the direction of the } \\
\text { OB/GYN or perinatologist. }\end{array}$ & $\begin{array}{l}\text { For the following patient } \\
\text { problems, the family physician } \\
\text { must obtain appropriate tests, } \\
\text { or obtain consultation from a } \\
\text { board certified obstetrician } \\
\text { gynecologist or appropriate } \\
\text { perinatal specialist. Patient care } \\
\text { responsibilities may be shared } \\
\text { if mutually agreeable to the } \\
\text { family physician and other } \\
\text { specialist. }\end{array}$ & $\begin{array}{l}\text { For the following patient } \\
\text { problems, the family } \\
\text { physician does not need to } \\
\text { obtain consultation if his/her } \\
\text { training and privileges allow } \\
\text { for managing these problems. } \\
\text { Complete documentation and } \\
\text { appropriate management of } \\
\text { these problems must be } \\
\text { apparent in the record. }\end{array}$ & $\begin{array}{l}\text { The newborn factors listed } \\
\text { below require immediate } \\
\text { assessment by the physician } \\
\text { and the initiation of } \\
\text { treatment and referral if } \\
\text { necessary. }\end{array}$ \\
\hline Initial prenatal factors & Initial prenatal factors & Initial prenatal factors & Major anomalies \\
\hline Multiple pregnancy & Age $>40$ or $<16$ & Habitual smoking & Respiratory distress \\
\hline Insulin-dependent diabetes & Drug dependency & $\begin{array}{l}\text { Single parent, questionable } \\
\text { social support }\end{array}$ & Five minute APGAR $<6$ \\
\hline Chronic hypertension & $\begin{array}{l}\text { High-risk family (lack of } \\
\text { family/social support)* }\end{array}$ & Height under 5 feet & Maternal pelvic infection \\
\hline Renal Failure & $\begin{array}{l}\text { Uterine or cervical } \\
\text { malformation or } \\
\text { incompetency }\end{array}$ & $\begin{array}{l}\text { Obesity (normal glucose } \\
\text { screening) }\end{array}$ & Small for gestational age \\
\hline $\begin{array}{l}\text { Heart disease (class II or } \\
\text { greater) }\end{array}$ & Contracted pelvis & Underweight & Macrosomia \\
\hline Hyperthyroidism & Previous cesarean section & Primigravida & Infant of a diabetic mother \\
\hline $\mathrm{Rh}$ isoimmunization & $\begin{array}{l}\text { Multiple spontaneous abortions } \\
(>3)\end{array}$ & $\begin{array}{l}\text { Second pregnancy in } 12 \\
\text { months }\end{array}$ & Hypoglycemia, hypocalcemia \\
\hline Chronic active hepatitis & Grand multiparity $(>8)$ & $\begin{array}{l}\text { History of congenital } \\
\text { abnormalities }\end{array}$ & Seizures \\
\hline Convulsive disorder & History of gestational diabetes & Family history of diabetes & $\begin{array}{l}\text { Prematurity, postmaturity, } \\
\text { dysmaturity }\end{array}$ \\
\hline $\begin{array}{l}\text { Isoimmune } \\
\text { thrombocytopenia }\end{array}$ & $\begin{array}{l}\text { Previous fetal or neonatal } \\
\text { demise }^{\dagger}\end{array}$ & Anemia (mild or moderate) & Meconium aspiration \\
\hline $\begin{array}{l}\text { Subsequent prenatal and } \\
\text { intrapartum factors }\end{array}$ & Hypothyroidism & $\begin{array}{l}\text { Medical problems (eg, } \\
\text { asthma, acid/peptic disease, } \\
\text { maternal infections) }\end{array}$ & Birth trauma \\
\hline $\begin{array}{l}\text { Vaginal bleeding ( } 2 \text { nd or } 3 \mathrm{rd} \\
\text { trimester) }\end{array}$ & Heart disease (class I) & $\begin{array}{c}\text { Subsequent prenatal and } \\
\text { intrapartum factors }\end{array}$ & \\
\hline $\begin{array}{l}\text { Preeclampsia (Toxemia) } \\
\text { Moderate or Severe }\end{array}$ & $\begin{array}{l}\text { Severe anemia (unresponsive } \\
\text { to } \mathrm{Fe} \text { ) }\end{array}$ & First trimester bleeding & \\
\hline $\begin{array}{l}\text { Fetal malformation, by AFP } \\
\text { screening, ultrasound or } \\
\text { amniocentesis }\end{array}$ & Pelvic mass of neoplasia & Urinary tract infection & \\
\hline $\begin{array}{l}\text { Abnormal presentation: } \\
\text { breech, face, brow, } \\
\text { transverse }\end{array}$ & $\begin{array}{c}\text { Subsequent prenatal and } \\
\text { intrapartum factors }\end{array}$ & Pelvic infection & \\
\hline $\begin{array}{l}\text { Intrauterine growth } \\
\text { retardation }\end{array}$ & Gestational diabetes & $\begin{array}{l}\text { Prenatal weight gain }>40 \text { lbs. } \\
\quad \text { or }<15 \text { lbs. }\end{array}$ & \\
\hline Hydramnios & Preeclampsia (toxemia) mild & $\begin{array}{l}\text { Prolonged latent phase or } \\
\text { labor }\end{array}$ & \\
\hline $\begin{array}{l}\text { Pregnancy }>43 \text { weeks or } \\
\quad<37 \text { weeks }\end{array}$ & $\begin{array}{l}\text { Pregnancy at } 41 \text { weeks, obtain } \\
\text { appropriate fetal/placental } \\
\text { tests }\end{array}$ & Meconium staining & \\
\hline Abnormal fetal/placental tests & Active genital herpes & $\begin{array}{l}\text { Pitocin augmentation of } \\
\text { labor }\end{array}$ & \\
\hline $\begin{array}{l}\text { Persistent severe variable or } \\
\text { late decelerations }\end{array}$ & $\begin{array}{l}\text { Positive high or low AFP } \\
\text { screen }\end{array}$ & $\begin{array}{l}\text { Outlet forceps or vacuum } \\
\text { extraction }\end{array}$ & \\
\hline Macrosomia & $\begin{array}{l}\text { Estimated fetal weight }>10 \mathrm{lbs} \\
\text { or }<6 \mathrm{lbs}\end{array}$ & $\begin{array}{l}\text { Repair of third or fourth } \\
\text { degree laceration }\end{array}$ & \\
\hline Cord prolapse & Abnormal non-stress test & Newborn resuscitation & \\
\hline Mid forceps delivery & $\begin{array}{l}\text { Arrest of normal labor curve } \\
\text { Persistent moderate variable } \\
\text { decelerations/poor baseline } \\
\text { variability } \\
\text { Ruptured membrane beyond } \\
24 \text { hours } \\
\text { Second stage beyond } 2 \text { hours } \\
\text { Induction of labor }\end{array}$ & Manual removal of placenta & \\
\hline
\end{tabular}

\footnotetext{
* Consultation may be with appropriate social service agency

${ }^{\dagger}$ Consultation may be with perinatal genetic counselor.
} 
delivery and submit every complicated delivery record, including those that went to cesarean section for any reason. The record submissions were required to include both the prenatal care and hospital portions of the obstetric record.

An Access database (Microsoft, Redmond, WA) was designed to monitor the physician members and their compliance with mandatory protocols. This database contains information on physician participation and demographics, submitted delivery record information, case analysis reviews, and attendance at sponsored CME seminars. Finally, participants were required to attend or to be represented by a call group member at one continuing medical education conference per year sponsored by the Liability Project.

Benefits to the participants included a $13 \%$ discount off their total malpractice premium, including both the obstetric and nonobstetric portion. This resulted in an annual discount of approximately $\$ 2000$ at the mature rate, depending on a variety of factors. Participants also received feedback from records that were reviewed by the physician reviewers and were able to participate in the continuing education conferences at no charge.

Data were collected on compliance with the above requirements 3 times per year. This included monitoring delivery log sheet submissions, record submissions, and annual evaluation of attendance at CME events. Record reviews were conducted by physician reviewers and included evaluation of 55 individual items from the prenatal and intrapartum portion of the patient records. Feedback from the reviews was sent to the participants to make them aware of risk factors with each delivery and the deficiencies in documentation. Physicians were not profiled and these data were not shared with the insurance carrier.

\section{Malpractice Cases}

In late December 1999 and again in January 2001, the insurance company reviewed all cases for obstetric events that occurred during the project period (1989 to 1998) to determine the number of project participants named. Any claim involving care rendered during the prenatal, intrapartum, or postpartum period against a project participant was included. The dollar amount of settlement was included in the report. For confidentiality and proprietary reasons, the company did not reveal the names of the participants and it was therefore impossible to profile those participants with a claim.

\section{Results}

A total of 194 physicians participated during the 10-year study period, for an annual average of 102 physicians per year, which accounted for 1020 physician-years of practice. One hundred and seventy physicians $(87.6 \%)$ practiced in northern or central California, including the San Francisco Bay area. One hundred and twelve physicians (57.7\%) practiced in either solo or 2-physician practices. Ninety-two physicians (48.3\%) practiced in rural settings. Nearly $97 \%$ of physicians were educated in US or Canadian medical schools; $94.3 \%$ of all physicians were residency-trained. There were 143 (73.7\%) male physicians and 51 (26.3\%) female physicians participating.

On average, physicians practiced for 5.5 years before joining the project. When the 62 physicians (31.9\%) who joined directly out of residency are excluded, the average practice years before joining the project for the remaining participants is 7.9 years. The mean length of time a physician participated as an active member of the project was 5 years. The median period of participation was 4 years. Although 194 different physicians participated during the 10-year period, 92 (47.5\%) physicians participated for at least 5 consecutive years and $18(9.3 \%)$ physicians participated for 10 years.

Forty-three physicians $(22.1 \%)$ eliminated obstetrics from their clinical practice over the course of the study, which was the most common reason for a physician to withdraw from the project. During the 10 -year period, 17 physicians $(8.7 \%)$ failed to comply with the required guidelines and were discharged from the project. Another 21 physicians $(10.8 \%)$ changed malpractice insurance carriers and subsequently withdrew from the study. Other reasons for leaving the project included retirement, moving out of state, and practice changes resulting in eliminating the physicians' responsibility for paying their own premiums. Claims information for physicians who either withdrew or were discharged because of their lack of compliance was still included in the claims analysis.

As noted above, compliance with record submissions averaged $91 \%$ per year (Table 2) with 32,831 deliveries reported during the 10 -year period. This translates to approximately 32 deliveries per year 
Table 2. Annual Participation and Practice Demographics

\begin{tabular}{|c|c|c|c|c|c|c|c|c|c|c|}
\hline \multirow[b]{2}{*}{ Year } & \multirow{2}{*}{$\begin{array}{l}\text { Physicians } \\
\text { Participants } \\
\text { (N) }\end{array}$} & \multicolumn{2}{|c|}{$\begin{array}{c}\text { Physicians } \\
\text { Submitting } \\
\text { Delivery Records }\end{array}$} & \multirow{2}{*}{$\begin{array}{l}\text { Deliveries } \\
\text { Recorded } \\
\text { (N) }\end{array}$} & \multicolumn{2}{|c|}{$\begin{array}{c}\text { Rural* } \\
\text { Physicians }\end{array}$} & \multicolumn{2}{|c|}{$\begin{array}{c}\text { Urban } \\
\text { Physicians }\end{array}$} & \multicolumn{2}{|c|}{$\begin{array}{c}\text { Solo or Two } \\
\text { Physician } \\
\text { Practices }\end{array}$} \\
\hline & & $\mathrm{N}$ & $\%$ & & $\mathrm{~N}$ & $\%$ & $\mathrm{~N}$ & $\%$ & $\mathrm{~N}$ & $\%$ \\
\hline 1989 & 74 & 66 & 89 & 2557 & 35 & 47 & 39 & 53 & 41 & 55 \\
\hline 1990 & 92 & 82 & 89 & 3347 & 48 & 52 & 44 & 48 & 56 & 61 \\
\hline 1991 & 97 & 93 & 96 & 3672 & 50 & 52 & 47 & 48 & 55 & 57 \\
\hline 1992 & 117 & 110 & 94 & 3995 & 54 & 46 & 63 & 54 & 67 & 57 \\
\hline 1993 & 119 & 111 & 93 & 4016 & 54 & 45 & 65 & 55 & 69 & 58 \\
\hline 1994 & 118 & 109 & 92 & 4187 & 57 & 48 & 61 & 52 & 62 & 53 \\
\hline 1995 & 114 & 109 & 96 & 3616 & 55 & 48 & 59 & 52 & 56 & 49 \\
\hline 1996 & 112 & 99 & 88 & 2816 & 57 & 51 & 55 & 49 & 55 & 49 \\
\hline 1997 & 98 & 81 & 83 & 2373 & 50 & 51 & 48 & 49 & 48 & 49 \\
\hline 1998 & 82 & 74 & 90 & 2252 & 34 & 42 & 48 & 58 & 42 & 51 \\
\hline $\mathrm{AVG}$ & 102 & 93 & 91 & 3283 & 49 & 48 & 53 & 52 & 55 & 54 \\
\hline
\end{tabular}

* Population density of less than 250 persons per square mile and not wholly containing an incorporated area of greater than 50,000 persons. Data source: Office of Statewide Planning and Development.

per physician. Compliance with record submissions averaged $93.9 \%$ among those physicians who participated in the study for $\geq 5$ years. A review of obstetric claims by the malpractice carrier revealed 5 closed cases on records involving participants during this same time period. This is a rate of 0.15 cases per 1000 births. Four cases resulted in any payment to the claimant. Three cases were settled for less than $\$ 30,000$ each, making them not reportable to the National Provider Data Bank. Two of these cases involved shoulder dystocia, and one involved a fetal demise (Table 3). A single case involving a delay in emergency cesarean section as a result of uterine rupture, complicated by a uterine infection and severe neonatal brain damage, settled for $\$ 950,000$.

The settlement total for all participants for the entire 10-year period was less than $\$ 1.1$ million, or an average of approximately $\$ 1078$ per participant per year, not including legal or administrative costs. Not included in the analysis was an additional claim against one of the physician participants that involved an ectopic pregnancy; it was settled for $\$ 13,000$. It was felt that this exposure did not result from the physician providing obstetric care, and the risk management intervention only covered patients known to be pregnant and accepted into prenatal care.

\section{Survey Results}

In 1992, at the 5-year point of the study, participants were asked questions about the impact of the project on their maternity care in their practice. Seventy-eight physicians of the 110 (70.9\%) who were participating at that time returned the survey. Forty-three $(55.1 \%)$ indicated they would have continued obstetrics in their practices regardless of the project's intervention. Twenty $(25.7 \%)$ indicated they would have discontinued the obstetric care portion of their practice or not accepted any new obstetrical patients without the project. Fifteen $(19.2 \%)$ indicated that without the project, they would have further limited the scope of their obstetric practice to lower risk patients than those for whom they were currently caring.

Sixty-seven participants $(85.9 \%)$ felt satisfied with the efforts of the program and found it beneficial to their practices. Seven participants (8.9\%)

Table 3. Malpractice Cases in Which There Was a Settlement

\begin{tabular}{llr}
\hline Loss Date & \multicolumn{1}{c}{ Nature of Claim } & Settlement \\
\hline $5 / 22 / 1992$ & Negligent prenatal care & $\$ 29,999$ \\
$2 / 10 / 1993$ & Fetal demise & $\$ 950,000$ \\
& Negligent prenatal care & $\$ 29,999$ \\
$1 / 17 / 1994$ & Uterine rupture delayed cesarean section, severe brain damage & $\$ 29,999$ \\
$7 / 21 / 1994$ & Negligent prenatal care & Shoulder dystocia resulting in brachial plexus injury \\
& Negligent prenatal care & \\
& Shoulder dystocia resulting in brachial plexus injury & \\
\hline
\end{tabular}


found the program not satisfactory, primarily because of the difficulty in attending required CME conferences; however, these physicians participated for an average of 8.2 years and remained active members for an additional 4 years after the survey was taken. The remaining 4 participants $(5.1 \%)$ had no opinion or did not respond to this question of the survey.

\section{Discussion}

Published reports continue to document the national crisis in malpractice premiums for physicians. In parts of the country, premiums have risen to such exorbitant levels that many family physicians in Mississippi, Florida, and Texas have dropped obstetrics care from their practices; in California, notwithstanding its model tort reform (MICRA), physicians still experienced a significant increase in premiums between 1988 and 1998. Physicians in West Virginia and Pennsylvania, however, have been hit hardest, with a $150 \%$ increase in their liability rates over the past several years. ${ }^{16-18}$

Although debates and efforts related to tort reform continue, risk management programs may help provide needed relief from the rising cost of malpractice premiums by decreasing suits. The results of this 10-year collaborative risk management project illustrate this line of reasoning with several points. First, family physicians that provide maternity care, when given minimal financial incentive, will participate in a risk management program and follow practice guidelines and submit records for review. A 91\% compliance with project guidelines is noteworthy given the fact that these physicians have no institutional affiliation and are geographically distributed across northern California. Second, physicians were in general satisfied with the project and felt that it was of benefit to their obstetrics practices. Third, although not a controlled trial, the experience of this project suggests that family physicians in this type of program can provide obstetric care with minimal risk of successful suit. Although data on closed claims for obstetrics care disaggregated by specialty is not readily available, the rate of 0.15 closed cases per 1000 births compares favorably with the rate of 0.32 claims per 1000 births found by Baldwin et $\mathrm{al}^{19}$ in a study of Washington State physicians. The rate in our study was 0.12 per 1000 births for suits resulting in any settlement and 0.03 per 1000 births for suits that result in a settlement large enough to result in a report to the National Provider Data bank. This may be even more significant to insurance carriers and family physicians considering providing obstetric care, particularly with settlement costs averaging approximately $\$ 1100$ per participant per year.

Three major risk management components were designed into this project, which possibly contributed to these results. The first was to define for participants what constituted a low-risk obstetric practice to guide them in accepting patients for prenatal care. The second element was the guidelines requiring consultation with a board-certified obstetrician for certain conditions that arise during prenatal and intrapartum care. The third element was the record review and feedback. This may have changed practice and/or documentation either in response to the feedback or because of an observer effect. In any event, the combination of elements in this project was acceptable to practicing physicians, and this group of physicians demonstrated a relatively low risk of successful suits.

Because physicians were not randomly selected, it is impossible to clearly attribute these results to the project. It is possible, for instance, that physicians who enroll in this type of program have a lower risk of successful suits than those who opt not to participate in such a program. If this is the case, however, it may be possible to select a group of family physicians who, when compliant with such a program, are at minimal risk of successful suits. California physicians benefit from tort reform limiting "pain and suffering" awards to $\$ 250,000$ (MICRA Act). This may have had an influence on amount of the single large award; however, it is unlikely that it would have affected the other smaller settlements, because they seem to have been negotiated to limit them to less than $\$ 30,000$. It could be argued that this type of program would have even larger economic benefits to liability carriers in other states, where there are no limits on awards. It is also important to note that half of these physicians were in rural practice, many in solo practice, which, under normal circumstances, would make it difficult to participate in peer review activities. This project effectively gave them the opportunity to become part of a large practice group with the associated benefits of peer review and collegial support that they experienced at the CME meetings. 
Further studies are needed on quality assurance interventions involving physicians providing maternity care to determine whether, in fact, outcomes are improved and malpractice risks are lowered. This study demonstrates that a successful collaborative model between a malpractice insurance carrier, university researchers, and practicing physicians may be instituted to evaluate risk management and quality assurance interventions, the implications of which are critical in the current malpractice environment.

\section{References}

1. Albert T. Malpractice awards pushing insurance premium higher. American Medical News 2001;44(9): 1-2. Available at: URL: http://www.ama-assn.org/ amednews/2001/03/05/prl10305.htm

2. Medical professional liability and the delivery of obstetrical care. Washington (DC): Institute of Medicine; 1989.

3. Nesbitt TS, Scherger JE, Tanji JL. The impact of obstetrical liability on access to perinatal care in the rural United States. J Rural Health 1989;5:321-35.

4. American Academy of Family Practice. Facts about Family Practice. Clinical practice components of family physicians by chapter. Kansas City (MO): American Academy of Family Practice; 1992.

5. Nesbitt TS, Baldwin LM. Access to obstetric care. Prim Care 1993;20:509-22.

6. Albert T. End-of-year action crucial: Pennsylvania faces liability meltdown. American Medical News 2002;45(46):1, 4.

7. Nesbitt TS, Rosenblatt RA, Connell FA, Hart LG. Access to obstetric care in rural areas: effect on birth outcomes. Am J Public Health 1990;80:814-8.
8. Nesbitt TS, Larson E, Rosenblatt RA, Hart LG. Access to maternity care in rural Washington: its effect on neonatal outcomes and resource use. Am J Public Health 1997;87:85-90.

9. Smucker DR. Obstetrics in family practice in the state of Ohio. J Fam Pract 1988;26:165-8.

10. Heland KV. Who will deliver our babies? Medical Malpractice Prevention 1987;Nov/Dec:48-50.

11. Smith MA, Howard KP. Choosing to do obstetrics in practice: factors affecting the decisions of thirdyear family practice residents. Fam Med 1987;19: 191-4.

12. Smith MA, Green LA, Schwenk TL. Family practice obstetrics in Michigan: factors affecting physician participation. J Fam Pract 1989;28:433-7.

13. American College of Obstetricians and Gynecologists. Professional liability and its effects: report of a 1987 survey of ACOG's membership. Washington (DC): American College of Obstetricians and Gynecologists; 1988.

14. Nesbitt TS, Kahn NB, Tanji JL, Scherger JE. Factors influencing family physicians to continue providing obstetric care. West J Med 1992;157:44-7.

15. Norton SA. The malpractice premium costs of obstetrics. Inquiry 1997;34(1):62-9.

16. Albert T, Adams D. Professional liability insurance rates go up, up; doctors go away. American Medical News 2002;45(1):1-2.

17. Armstrong J. Malpractice rates leading doctors to drop coverage. Physicians Financial News 2002; 20(7):1, 35

18. Albert T. Soaring premiums force doctors to close practice. American Medical News 2001;44(34):1-2.

19. Baldwin LM, Larson EH, Hart LG, Greer T, Lloyd $M$, Rosenblatt RA. Characteristics of physicians with obstetric malpractice claims experience. Obstet Gynecol 1991;78:1050-4. 